\title{
Self-reported nonrestorative sleep in fibromyalgia - relationship to impairments of body functions, personal function factors, and quality of life
}

This article was published in the following Dove Press journal: Journal of Pain Research

10 August 2015

Number of times this article has been viewed

\section{Gunilla M Liedberg' \\ Mathilda Björk ${ }^{2}$ \\ Björn Börsbo ${ }^{3}$}

'Department of Social and Welfare Studies, Linköping University, Norrköping, ${ }^{2}$ Rehabilitation Centre and Department of Medical and Health Sciences, ${ }^{3}$ Rehabilitation Medicine, Department of Medicine and Health Sciences (IMH), Linköping University, Linköping, Sweden
Correspondence: Björn Börsbo Rehabilitation Medicine, Department of Medicine and Health Sciences, Linköping University, SE-58I 85 Linköping, Sweden Tel +4670792 2161

Email bjorn.borsbo@liu.se
Purpose: The purpose of this study was: 1) to determine variables that might characterize good or bad sleep; and 2) to describe the relationship between sleep, impairment of body functions, personal function factors, and quality of life based on quality of sleep in women with fibromyalgia (FM).

Methods: This cross-sectional descriptive study included 224 consecutive patients diagnosed at a specialist center. These patients were mailed a questionnaire concerning sleep, body functions, personal factors, and health-related quality of life. In total, 145 completed questionnaires were collected.

Results: Using sleep variables (sleep quality, waking up unrefreshed, and tiredness when getting up), we identified two subgroups - the good sleep subgroup and the bad sleep subgroup - of women with FM. These subgroups exhibited significantly different characteristics concerning pain intensity, psychological variables (depressed mood, anxiety, catastrophizing, and selfefficacy), impairments of body functions, and generic and health-related quality of life. The good sleep subgroup reported a significantly better situation, including higher employment/ study rate. The bad sleep subgroup reported a greater use of sleep medication. Five variables determined inclusion into either a good sleep or a bad sleep subgroup: pain in the evening, self-efficacy, anxiety, and according to the Short Form health survey role emotional and physical functioning.

Conclusion: This study found that it was possible to identify two subgroups of women with FM based on quality of sleep variables. The two subgroups differed significantly with respect to pain, psychological factors, impairments of body functions, and perceived quality of life, where the subgroup with bad sleep had a worse situation.

Keywords: activities of daily living, chronic pain, sleep disturbance

\section{Introduction}

In Western populations, the prevalence of fibromyalgia (FM) is approximately $2 \%-5 \% .^{1-4}$ and the diagnosis is six times more common in women than men. ${ }^{1}$ In addition to experiencing pain, FM patients experience fatigue, cognitive dysfunction, stiffness, mood disturbances, and nonrestorative sleep. ${ }^{5-7}$ Guymer et al $^{8}$ showed that fatigue levels were significantly influenced by age and sleep disturbances, and sleep disturbances were significantly predicted by fatigue. In two studies, more than $90 \%$ of FM patients reported disturbed and nonrestorative sleep..${ }^{910}$ In addition, FM patients have reported difficulties falling or staying asleep, nonrestorative sleep, and waking up early in the morning. ${ }^{10,11}$ According to Moldofsky, ${ }^{10}$ nonrestorative sleep is not the same as insomnia, as it is essentially a qualitative phenomenon. Restorative or refreshing 
sleep depends on the amount one sleeps and when one sleeps. People who experience nonrestorative sleep characterize their sleep as light or superficial. ${ }^{10}$

According to the American College of Rheumatology (ACR), three core symptoms of nonrestorative sleep should be used when diagnosing FM: waking up feeling unrefreshed; cognitive difficulties; and fatigue. ${ }^{12}$

Sleep duration and nightly wake time did not, according to Anderson et al, ${ }^{13}$ predict clinical FM pain, although Schaefer et $\mathrm{al}^{9}$ showed that sleep disturbance measured by Medical Outcomes Study Sleep Scale increased significantly in severe FM. Furthermore, Roizenblatt et al ${ }^{14}$ described that compared with healthy controls, most patients with FM perceived their sleep to be of poor quality, reporting it as nonrestorative, and reported worsening pain symptoms after nonrestorative sleep. Bigatti et $\mathrm{al}^{15}$ found that FM patients exhibited persistent poor sleep quality, for instance, sleep duration and sleep latency, that eventually leads to increased pain, disability, and depression. A causal relationship and interaction may exist between FM, sleep, and mood disorders. ${ }^{16}$

Sleep disturbances can affect a patient's health-related quality of life (HRQoL); a comparison between matched controls and persons with FM showed a statistically significant difference between sleep difficulty symptoms, such as initiating and maintaining sleep, and HRQoL. ${ }^{17}$ Consequences of the sleep difficulty symptoms such as social isolation and decreased physical activity were shown to severely impact HRQoL and, further, the effect extended beyond HRQoL. ${ }^{17}$ The impact of symptoms was also shown in an interview study investigating general quality of life of working women with FM. The women highlighted the importance of having social relations, being active, and participating in society as essential for experiencing general quality of life. ${ }^{18}$

The aim of this study was: 1$)$ to determine variables that might characterize good or bad sleep; and 2) to describe the relationship between sleep, impairment of body functions, personal function factors, and quality of life based on quality of sleep in women with FM.

\section{Methods}

The project was approved by the Research Ethics Committee of the Faculty of Health Sciences, Linköping University, Sweden.

\section{Design}

This study used a cross-sectional, descriptive design. ${ }^{19}$ The participants completed a mailed questionnaire and instruments. The participants were sent a reminder 8 weeks after receiving the questionnaire and instruments.

\section{Participants}

Participants diagnosed with FM according to the 1990 ACR criteria $^{20}$ were consecutively enrolled from a pain clinic at a university hospital in southeast Sweden. In total, 224 consecutive patients were mailed a questionnaire. Eight weeks later a reminder was sent to the 93 patients who did not respond in the first instance. In the end, 173 (77\%) responded and 28 (13\%) did not want to participate in the study. In addition, $51(23 \%)$ people did not respond at all, leaving $145(64 \%)$ completed questionnaires available for the study.

\section{Data collection instruments}

Background variables included sex, age, family (marital status, children living at home), education (number of years), and employment/studies (full or part time). Further, medication usage was reported in an open-ended question.

\section{Impairments of body functions}

Questions about the participants' time since diagnosis, duration of symptoms, and pain characteristics (occurrence and alterations in pain) were included in the questionnaire. The participants indicated their perception of pain on a $10 \mathrm{~cm}$ visual analogue scale anchored at "no pain" and "worst imaginable pain". Visual analogue scale was also used to assess quality of sleep ("How was your sleep during the night?") from "very good" to "extremely bad", freshness in the morning ("How refreshed do you feel in the morning?") from "completely rested" to "not rested at all", and degree of tiredness ("How tired do you feel when getting up?") from "no tiredness" to "worst imaginable tiredness". Questions on depressed mood and fatigue were rated on a four-grade scale: "no, hardly ever"; "no, seldom"; "yes, sometimes"; and "yes, often".

\section{Personal function factors}

The fibromyalgia impact questionnaire (FIQ) measures the impact of the syndrome and includes questions on physical function, symptoms, interference of pain with work, sick leave, and the number of days the person felt well during the previous week. Each item is standardized on a scale between 0 and 10 points. ${ }^{21} \mathrm{~A}$ higher score indicates greater impact. The Swedish version of the instrument has been validated. ${ }^{22}$

The Coping Strategy Questionnaire consists of six subscales that assess patient self-rated use of cognitive and behavioral strategies to cope with pain. ${ }^{23}$ Each coping strategy 
subscale consists of six items measured with a numerical rating scale indicating how frequently the strategy was used to cope with pain. An additional two single-item questions assessed effectiveness ratings of control over pain and ability to decrease pain. The Coping Strategy Questionnaire takes approximately 5 minutes to complete. The instrument has been tested in women with $\mathrm{FM},{ }^{24}$ and the subscales have been shown to be reliable, valid, and sensitive to change. In this study, the subscale "catastrophizing" was used.

The Beck Anxiety Inventory contains 21 items that measure physiological and emotional symptoms of anxiety and discriminates symptoms of anxiety from those of depression. ${ }^{25}$ Scores can range from 0 to 63 with higher scores indicating more anxiety. The scale was translated into Swedish in a previous study, ${ }^{26}$ which indicated that the scale was internally consistent (Cronbach's alpha $=0.88$ ) and had a correlation of $r=0.49$ with the FIQ anxiety item.

The Arthritis Self-Efficacy Scale (ASES) is a 21-item scale divided into three subscales on which patients rate their ability to perform specific activities using a scale of $10 \%-100 \%$ surety. ${ }^{27}$ The subscales include items on control of pain and the ability to do physical activities and other functions, such as ability to handle fatigue. Higher scores indicate higher self-efficacy. The scale has been validated in the Swedish version. ${ }^{28}$

\section{Quality of life}

The Quality of Life Scale, Swedish version (QOLS-S) is composed of 16 items that together describe quality of life using six categories: physical and material well-being; health; relations with other people; personal development and fulfilment; recreation; and independence. ${ }^{29}$ Patients estimate satisfaction with their current situation on a seven-point Likert-type scale; the higher the total score, the higher the degree of satisfaction. Preliminary psychometric testing in Sweden reported good internal consistency reliability ( $r=0.84$ for a 4 -week interval) and evidence of construct validity (alpha $=0.82$ at time I and alpha $=0.88$ at time II) in rheumatic disease populations. ${ }^{29} \mathrm{~A}$ descriptive review of the QOLS-S ${ }^{30}$ reviewed the entire body of work to date, while another study ${ }^{31}$ described construct validity using a larger sample of chronically ill and healthy subjects in the US and Sweden. Construct validity was also tested in a Swedish sample of 113 women with $\mathrm{FM},{ }^{32}$ and the content validity was tested using focus group methodology. ${ }^{19}$

The 36-Item Short-Form Health Survey (SF-36) measures health status in eight domains: physical functioning; role physical; bodily pain; general health; vitality; social functioning; role emotional; and mental health. ${ }^{33}$ The scale ranges from 0 to 100, where a higher score indicates better health status. The Swedish version of the SF-36 has been validated. ${ }^{34}$

\section{Statistics}

Descriptive statistics were used to describe the characteristics of the sample, and differences between groups were identified using the Mann-Whitney $U$ test for independent groups or the chi-square statistics for nominal variables.

The three sleep variables - "sleep quality", "waking up refreshed", and "tiredness when getting up" - were submitted to K-means cluster analysis. An iterative procedure was done in which each participant's values were repeatedly assigned to cluster membership on the basis of distance to the center. The analysis resulted in two separated clusters. The K-means model was chosen since it is a well-known method for data mining to establish the most homogeneous groups.

A discriminant analysis was done with cluster membership as the grouping variable and pain intensity, fatigue, depressed mood, anxiety, self-efficacy, catastrophizing, physical function, and quality of life as independent variables. All analyses were done using SPSS version 20.0 (IBM Corporation, Armonk, NY, USA); $P$-values $<0.05$ were considered significant.

\section{Results}

The cluster analysis resulted in two subgroups. As intended, the two subgroups differed significantly on all three grouping variables. The first subgroup $(n=43)$ - good sleep - was characterized by scoring good sleep quality (mean value $[\mathrm{m}]=3.8)$, waking up refreshed $(\mathrm{m}=4.2)$, and not so tired when getting up $(m=3.9)$. The second subgroup $(n=102)-$ bad sleep - was characterized by scoring bad sleep quality $(\mathrm{m}=7.0)$, waking up unrefreshed $(\mathrm{m}=8.4)$, and tired when getting up $(\mathrm{m}=7.8)$ (Table 1).

Table 2 presents demographics and medication usage. When comparing the background variables for the two subgroups, we found no significant differences in age, marital status, number of children living at home, or pain duration. The good sleep subgroup had a significantly higher proportion of women with university education than the bad sleep subgroup. The good sleep subgroup also had significantly higher employment/study rate, and more of these women worked full time. The bad sleep subgroup reported significantly higher usages of sleep medication.

The two subgroups were investigated for possible differences concerning pain variables. Compared to the good sleep subgroup, the bad sleep subgroup scored significantly 
Table I Groups, "good sleep” and "bad sleep”, based on K-means cluster analysis on the following sleep variables: "sleep quality", "waking up unrefreshed", and "tiredness when getting up"

\begin{tabular}{|c|c|c|c|c|c|c|}
\hline \multirow[t]{3}{*}{ Variables } & \multicolumn{5}{|c|}{ Group } & \multirow[t]{3}{*}{ Scdfe } \\
\hline & \multicolumn{2}{|c|}{$\begin{array}{l}\text { Good sleep } \\
(n=43)\end{array}$} & \multicolumn{2}{|c|}{$\begin{array}{l}\text { Bad sleep } \\
(n=102)\end{array}$} & \multirow[t]{2}{*}{$P$-value } & \\
\hline & Mean & $\overline{\text { SD }}$ & Mean & $\overline{S D}$ & & \\
\hline \multicolumn{7}{|l|}{ Sleep } \\
\hline Quality & 3.8 & 2.0 & 7.0 & 1.9 & $<0.001$ & \\
\hline $\begin{array}{l}\text { Waking up } \\
\text { unrefreshed }\end{array}$ & 4.2 & 2.1 & 8.4 & 1.2 & $<0.001$ & \\
\hline $\begin{array}{l}\text { Tiredness when } \\
\text { getting up }\end{array}$ & 3.9 & 1.7 & 7.8 & 1.2 & $<0.001$ & \\
\hline \multicolumn{7}{|l|}{ Pain } \\
\hline In the morning & 4.8 & 2.5 & 6.7 & 2.0 & $<0.001$ & 0.25 \\
\hline In the evening & 5.4 & 2.3 & 6.9 & 1.8 & $<0.001$ & 0.34 \\
\hline $\begin{array}{l}\text { Worst during } \\
\text { the day }\end{array}$ & 5.8 & 2.4 & 7.4 & 1.7 & $<0.001$ & -0.18 \\
\hline Mean during day & 4.6 & 2.1 & 6.0 & 1.7 & $<0.001$ & -0.14 \\
\hline During movement & 4.8 & 2.4 & 6.6 & 1.9 & $<0.001$ & -0.07 \\
\hline At rest & 3.8 & 2.4 & 5.6 & 2.0 & $<0.001$ & 0.17 \\
\hline Depressed mood & 2.4 & 0.9 & 2.9 & 0.9 & 0.003 & -0.07 \\
\hline Fatigue & 3.1 & 0.8 & 3.7 & 0.5 & $<0.001$ & 0.11 \\
\hline BAI & 6.1 & 5.6 & 15.3 & 10.9 & $<0.001$ & 0.33 \\
\hline CSQ catastrophizing & 7.4 & 6.0 & 13.3 & 8.6 & $<0.001$ & -0.14 \\
\hline FIQ & 53.3 & 18.2 & 61.9 & 17.2 & 0.011 & 0.13 \\
\hline \multicolumn{7}{|l|}{ ASES } \\
\hline Pain & 57.8 & 19.1 & 40.3 & 17.9 & $<0.001$ & 0.20 \\
\hline Function & 78.2 & 16.5 & 60.3 & 20.4 & $<0.001$ & -0.12 \\
\hline Symptoms & 66.6 & 17.0 & 46.4 & 16.8 & $<0.001$ & -0.52 \\
\hline QOLS-S & 85.7 & 13.7 & 73.6 & 14.9 & $<0.001$ & -0.01 \\
\hline \multicolumn{7}{|l|}{ SF-36 } \\
\hline Physical function & 59.3 & 19.4 & 43.6 & 17.2 & $<0.001$ & -0.30 \\
\hline Role physical & 32.7 & 36.8 & 11.4 & 19.2 & $<0.001$ & -0.15 \\
\hline Role emotional & 66.7 & 42.9 & 49.3 & 45.5 & 0.039 & 0.35 \\
\hline Social function & 69.2 & 25.6 & 49.9 & 25.0 & $<0.001$ & 0.07 \\
\hline Bodily pain & 39.3 & 18.5 & 26.5 & 14.1 & $<0.001$ & 0.08 \\
\hline Vitality & 42.2 & 19.2 & 21.8 & 16.8 & $<0.001$ & -0.29 \\
\hline Mental health & 74.7 & 15.7 & 60.2 & 22.1 & $<0.001$ & -0.19 \\
\hline General health & 46.6 & 22.5 & 35.4 & 18.3 & 0.006 & 0.15 \\
\hline
\end{tabular}

Notes: The two groups have been compared with respect to the variables below the Sleep section. Mean values \pm one SD are reported. For statistical comparison of the groups, Mann-Whitney $U$ test was used; $P$-values are given, and $P \leq 0.05$ was regarded as significant. Scdfc are given.

Abbreviations: BAl, Beck Anxiety Inventory; CSQ, Coping Strategy Questionnaire; FIQ, fibromyalgia impact questionnaire; ASES, Arthritis Self-Efficacy Scale; QOLS-S, Quality of life Scale, Swedish version; Scdfc, standardized canonical discriminant function coefficients; SD, standard deviation; SF-36, The 36-Item Short-Form Health Survey.

higher on all pain variables (pain in the morning, pain in the evening, pain at worst during the day, mean pain during the day, pain when moving, and pain at rest). In addition, the bad sleep subgroup had significantly higher anxiety scores (Beck Anxiety Inventory). The good sleep group showed a higher degree of self-efficacy compared to the bad sleep subgroup, a difference that was significant.
Table 2 Background variables of the whole group of women with fibromyalgia and the subgroups "good sleep" and "bad sleep", based on K-means cluster analysis on the sleep variables: "sleep quality", "waking up unrefreshed", and "tiredness when going up"

\begin{tabular}{|c|c|c|c|c|}
\hline Variables & $\begin{array}{l}\text { Total } \\
(n=\mid 45)\end{array}$ & $\begin{array}{l}\text { Good sleep } \\
(n=43)\end{array}$ & $\begin{array}{l}\text { Bad sleep } \\
(n=102)\end{array}$ & $P$-value \\
\hline $\begin{array}{l}\text { Age, years, } \\
\text { mean (SD) }\end{array}$ & $47.0(10.1)$ & $47.0(10.1)$ & $47.4(10.2)$ & ns \\
\hline Family, n (\%) & & & & ns \\
\hline Single & $28(19)$ & $10(23)$ & $18(18)$ & \\
\hline Married & $116(80)$ & $33(77)$ & $82(80)$ & \\
\hline Missing Answers & $\mathrm{I}(\mathrm{I})$ & $0(0)$ & $2(2)$ & \\
\hline $\begin{array}{l}\text { Children living at } \\
\text { home, } n(\%)\end{array}$ & & & & ns \\
\hline Yes & $66(45)$ & $20(47)$ & $45(44)$ & \\
\hline No & $66(45)$ & $18(42)$ & $48(47)$ & \\
\hline Missing Answers & $13(10)$ & $5(\mathrm{II})$ & $9(9)$ & \\
\hline Education, n (\%) & & & & $<0.05$ \\
\hline 9 years & $42(29)$ & $10(23)$ & $32(3 I)$ & \\
\hline 12 years & $74(5 I)$ & $18(42)$ & $55(54)$ & \\
\hline University & $26(18)$ & $13(30)$ & $13(13)$ & \\
\hline Missing Answers & $3(2)$ & $2(5)$ & $2(2)$ & \\
\hline $\begin{array}{l}\text { Employment/ } \\
\text { studies, n (\%) }\end{array}$ & & & & $<0.001$ \\
\hline Full time & $17(12)$ & $10(23)$ & $7(7)$ & \\
\hline Part time & $40(28)$ & $8(19)$ & $32(3 I)$ & \\
\hline $\begin{array}{l}\text { Not working/ } \\
\text { studying }\end{array}$ & $88(60)$ & $25(58)$ & $63(62)$ & $<0.05$ \\
\hline \multicolumn{5}{|l|}{$\begin{array}{l}\text { Sleep medication, } \\
\mathrm{n}(\%)\end{array}$} \\
\hline Yes & $26(18)$ & $3(7)$ & $23(22)$ & \\
\hline No & $119(82)$ & $40(93)$ & 79 (78) & \\
\hline
\end{tabular}

Notes: For statistical comparison of the subgroups Mann-Whitney $U$ test was used; $P$-values are given, and $P \leq 0.05$ was regarded as significant.

Abbreviations: ns, nonsignificant; SD, standard deviation.

As assessed by FIQ, the bad sleep subgroup reported a significantly greater impact of FM on daily living. In addition, the bad sleep subgroup reported a significantly higher degree of catastrophizing.

General health, general quality of life, and HRQoL were assessed by QOLS-S, SF-36, and the item "general health last week". All scales showed a significant difference between the two subgroups: the good sleep subgroup reported a better perceived general health, general quality of life, and HRQoL than the bad sleep subgroup (Table 1).

The discriminant analysis resulted in a significant model $(P<0.001)$ where ASES symptoms, pain in the evening, anxiety, role emotional, and physical function, according to SF-36 had the highest predictive loading for group belonging based on the standardized canonical discriminant function coefficients (Table 1). The model correctly classified $84.5 \%$ of the original grouped cases and $74.5 \%$ of the cross-validated cases. 


\section{Discussion}

This cross-sectional study investigated the relationships between sleep in women with FM and impairment of body functions, personal function factors, and quality of life, and described the characteristics of different subgroups based on sleep. Five major findings were identified:

- Using sleep variables, we identified subgroups in a group of female patients with FM.

- The two subgroups showed significantly different characteristics concerning pain intensity, psychological variables, impairment, and quality of life: the good sleep subgroup reported a significantly better situation than the bad sleep subgroup.

- The good sleep subgroup had a higher employment/study rate than the bad sleep subgroup.

- The bad sleep subgroup used more sleep medication than the good sleep subgroup.

- The variables (according to the discriminant analysis) determining which subgroup the patients belonged to were the ASES subscale "symptoms", pain in the evening, anxiety, and role emotional and physical function according to SF-36.

In this study, $70 \%$ of the women reported nonrestorative sleep, a finding that is similar to Consoli et $\mathrm{a} \mathrm{l}^{35}$ who reported a frequency of $75 \%$. However, this percentage is still a somewhat lower number compared to the cross-sectional study performed by Schaefer et al. ${ }^{9}$ Eighty-one percent of their participants reported nonrestorative sleep and $90 \%$ of the general population with FM reported nonrestorative sleep. ${ }^{10}$ Compared to the studies of Schaefer et $\mathrm{al}^{9}$ and Consoli et al, ${ }^{35}$ the women in our study were of the same age and worked outside their home to the same degree. Therefore, differences in sleep disturbances may be due to different measures used to investigate sleep problems.

There were no differences in either age or children living at home between the two groups in our study. Previous research has shown that having children living at home makes it difficult for women with FM to work. ${ }^{36}$ The good sleep subgroup had higher education and more were working outside their homes. These two factors may imply that the higher education, the more possibility the women had to control and influence their work situation and experience a supportive environment, resulting in better and more opportunities to remain in a work role. ${ }^{37}$ White and Harth ${ }^{2}$ also showed that education level was a predictor for work capacity, and Bigatti et a $\mathrm{l}^{15}$ found that higher education predicted better sleep. Hence, good sleep may influence the possibility to remain employed and, in that way, being able to experience participation in society. In this study, $40 \%$ of the women worked outside their homes, which is in reasonable agreement with other reports where work disability varies from $25 \%$ to $50 \%$ in patients with prolonged or chronic pain..$^{38}$ The bad sleep subgroup were more often employed part time compared with the good sleep subgroup, a difference that may have indicated that sleep disturbances negatively influenced work.

The bad sleep subgroup had a significantly worse situation concerning pain intensity in all variables (ie, in the morning, evening, at worst and mean during the day, when moving, and at rest). Roizenblatt et a ${ }^{14}$ and Bigatti et a ${ }^{15}$ found that sleeping problems lead to more severe pain. Furthermore, Anderson et $\mathrm{al}^{13}$ found that sleep problems may have an important role in the maintenance of pain since there may be a reciprocal relationship between sleep disorders and pain as sleep disturbance can be regarded as both a consequence of and a causal or maintenance mechanism for pain.

Some studies have suggested that non-benzodiazepine hypnotics can improve sleep and possibly fatigue in FM patients. ${ }^{39,40}$ The frequency of hypnotic medication use in our study might seem quite low: $22 \%$ in the bad sleep subgroup and $7 \%$ in the good sleep subgroup. However, population surveys show that between $0.7 \%$ and $7 \%$ of adults reported use of hypnotics, ${ }^{41}$ and $28 \%$ of people with major current insomnia used sleepenhancing medication. ${ }^{42}$ Thus, not all people experiencing poor sleep try to solve their problem by using hypnotic drugs or are not offered medication by their physician. This also seems to be the case among patients with FM in this study. According to Spaeth et al, ${ }^{43}$ the first step is to obtain the patient's sleep history, such as activities before sleep, attitudes toward sleep, dietary and other intakes, daytime activities, and information about sleep initiation, perpetuation, and duration. Furthermore, it is recommended that nonpharmacological therapies should be considered as the first-line treatment for FM.

Results in this study agrees with the results of Wagner et $\mathrm{al}^{17}$ who showed that sleep disturbances affected persons with FM, an obvious HRQoL of issue. In this study, a generic quality of life measure (QOLS-S) was also used to add information about quality of life in general, and the bad sleep subgroup showed a worse situation even here. This may suggest that a nonrestorative sleep impacted their whole life situation extending beyond HRQoL; meaning that social relations, the possibility of being active, and the ability to participate in society were affected. The bad sleep subgroup showed a statistically significantly worse situation in all variables (impairment of body functions and personal function factors) measured in this study and may explain the lower quality of life. 
In this study, it was also obvious that people's ability to control and manage their own situation was of significant importance for their sleep problems, where a lower selfefficacy leads to a worse situation concerning perceived sleep. Anxiety compared with depressed mood showed a significantly higher importance in this study. Previous studies - eg, Bigatti et $\mathrm{al}^{15}$ - showed that poor sleep quality can lead to depression. In this study, we did not use a specific validated depression scale and that may be a weakness. Still, we used questions concerning depressed mood used in previous studies. This may explain the different results, as variables are measured in different ways.

The discriminant analysis resulted in a significant model $(P<0.001)$ where a lower self-efficacy, physical functioning, and role emotional according to the SF-36, and a higher level of anxiety had the highest predictive loading for group belonging, findings that suggest that factors such as impairment of body functions, but especially personal function factors, are of importance for a nonrestorative sleep and should be considered to a greater extent in health care.

\section{Limitations}

The participants were drawn from a clinic at tertiary health care level and may thus represent more disabled people than could be expected in a general FM population. The data may not be representative for persons managed in the primary care setting.

This cross-sectional study has some limitations: the results are only confined to a specific time and the people with FM are not a homogenous group. These limitations may have influenced the results and should be taken into consideration as the women only reported their state of health and their difficulties at the time of the cross-sectional study. While analyzing data, we have not corrected for multiple comparisons. Instead, all of the individual $P$-values have been reported, in line with Rothman's ${ }^{44}$ suggestion to make the analyses transparent.

A weakness in this study is the lack of not using validated sleep and depression questionnaires. Since the investigations with the questionnaire and enclosed instruments were extensive, we choose to use some specific questions investigating nonrestorative sleep and depression.

\section{Conclusion}

This study found that it was possible to identify two subgroups of women with FM based on quality of sleep variables. The two subgroups differed significantly with respect to pain, psychological factors, impairments of body functions, and perceived quality of life, where the subgroup with bad sleep had a worse situation. It is important to assess and address sleep problems with a holistic approach in clinical practice so as to gain adequate treatment and a better whole life situation for patients with FM.

\section{Disclosure}

The authors report no conflicts of interest in this work.

\section{References}

1. Wolfe F, Ross K, Anderson J, Russel IJ, Hebert L. The prevalence and characteristics of fibromyalgia in the general population. Arthritis Rheum. 1995;38:19-28.

2. White KP, Harth M. Classification, epidemiology, and natural history of fibromyalgia. Curr Pain Headache Rep. 2001;5(4):320-329.

3. Lawrence RC, Felson DT, Helmick CG, et al. Estimates of the prevalence of arthritis and other rheumatic conditions in the United States. Part II. Arthritis Rheum. 2008;58(1):26-35.

4. Branco JC, Bannwarth B, Failde I, et al. Prevalence of fibromyalgia: a survey in five European countries. Semin Arthritis Rheum. 2010; 39(6):448-453.

5. Arnold LM, Crofford LJ, Mease PJ, et al. Patient perspectives on the impact of fibromyalgia. Patient Educ Couns. 2008;73(1):114-120.

6. Arnold LM, Clauw DJ, McCarberg BH; FibroCollaborative. Improving the recognition and diagnosis of fibromyalgia. Mayo Clin Proc. 2011; 86(5):457-464.

7. Choy EH, Mease PJ. Key symptom domains to be assessed in fibromyalgia (outcome measures in rheumatoid arthritis clinical trials). Rheum Dis Clin North Am. 2009;35(2):329-337.

8. Guymer EK, Maruff P, Littlejohn GO. Clinical characteristics of 150 consecutive fibromyalgia patients attending an Australian public hospital clinic. Int $J$ Rheum Dis. 2012;15:348-357.

9. Schaefer C, Chandran A, Hufstader M, et al. The comparative burden of mild, moderate and severe fibromyalgia: results from a cross-sectional survey in the United States. Health Qual Life Outcomes. 2011;9:71.

10. Moldofsky H. The significance, assessment, and management of nonrestorative sleep in fibromyalgia syndrome. CNS Spectr. 2008;13 (3 Suppl 5):22-26.

11. Mease P, Arnold LM, Bennet R, et al. Fibromyalgia syndrome. $J$ Rheumatol. 2007;34(6):1415-1425.

12. Wolfe F, Clauw DJ, Fitzcharles MA, et al. The American College of Rheumatology preliminary diagnostic criteria for fibromyalgia and measurement of symptom severity. Arthritis Care Res (Hoboken). 2010;62(5):600-610.

13. Anderson RJ, McCrae CS, Staud R, Berry RB, Robinson ME. Predictors of clinical pain in fibromyalgia: examining the role of sleep. J Pain. 2012;13(4):350-358.

14. Roizenblatt S, Moldofsky H, Benedito-Silva AA, Tufik S. Alpha sleep characteristics in fibromyalgia. Arthritis Rheum. 2001;44(1): 222-230.

15. Bigatti SM, Hernandez AM, Cronan TA, Rand KL. Sleep disturbances in fibromyalgia syndrome: relationship to pain and depression. Arthritis Rheum. 2008;59(7):961-967.

16. Arnold LM, Bradley LA, Clauw DJ, Glass JM, Goldenburg DL. Evaluating and diagnosing fibromyalgia and comorbid psychiatric disorders. J Clin Psychiatry. 2008;69(10):e28.

17. Wagner JS, DiBonaventura MD, Chandran AB, Cappelleri JC. The association of sleep difficulties with health-related quality of life among patients with fibromyalgia. BMC Musculoskelet Disord. 2012; 13:199.

18. Liedberg GM, Eddy L, Burckhardt CS. Validity testing of quality of life scale, Swedish version; Focus groups interviews of women with fibromyalgia. Occup Ther Int. 2012;19(4):167-175. 
19. Kerlinger FN, Lee HB. Foundations of Behavioral Research (PSY 200 (300) Quantitative Methods in Psychology). 4th ed. 200. Orlando: Harcourt College Publishers; 1999.

20. Wolfe F, Smythe HA, Yunus MB, et al. The American College of Rheumatology 1990 Criteria for the Classification of Fibromyalgia. Report of the Multicenter Criteria Committee. Arthritis Rheum. 1990;33: $160-172$.

21. Burckhardt CS, Clark SR, Bennet RM. The fibromyalgia impact questionnaire: development and validation. J Rheumatol. 1991;18: 728-733.

22. Hedin PJ, Hamne M, Burckhardt CS, Engström-Laurent A. The Fibromyalgia Impact Questionnaire, a Swedish translation of a new tool for evaluation of the fibromyalgia patient. Scand J Rheumatol. 1995;24:69-75.

23. Rosenstiel AK, Keefe FJ. The use of coping strategies in chronic low back pain patients: relationship to patient characteristics and current adjustment. Pain. 1983:17:33-44.

24. Burckhardt CS, Henriksson CM. The Coping Strategies Questionnaire Swedish version: evidence of reliability and validity in patients with fibromyalgia. Scandinavian Journal of Behaviour Therapy. 2001;30:97-107.

25. Beck AT, Epstein N, Brown G, Steer RA. An inventory for measuring clinical anxiety: psychometrics properties. J Consult Clin Psychol. 1988;56:893-897.

26. Burckhardt CS, Liedberg GM, Henriksson CM, Kendall S. The impact of fibromyalgia on employment status of newly-diagnosed young women: a pilot study. J Musculoskelet Pain. 2005;13:31-41.

27. Lorig K, Chastain RL, Ung E, Shoor S, Holman HR. Development and evaluation of a scale to measure perceived self-efficacy in people with arthritis. Arthritis Rheum. 1989;32:37-44.

28. Lomi C, Nordholm LA. Validation of a Swedish version of the Arthritis Self-efficacy Scale. Scand J Rheumatol. 1992;21:231-237.

29. Burckhardt CS, Archenholtz B, Bjelle A. Measuring the quality of life of women with rheumatoid arthrithis or systemic lupus erythematosus: a Swedish version of the Quality of Life Scale (QOLS). Scand J Rheumatol. 1992,21:190-195.

30. Burckhardt CS, Anderson KL. The Quality of Life scale (QOLS): reliability, validity, and utilization. Health Qual Life Outcomes. 2003;1:60.

31. Burckhardt CS, Anderson KL, Archenholtz B, Hägg O. The Flanagan Quality of Life Scale: evidence of construct validity. Health Qual Life Outcomes. 2003;1:59.
32. Liedberg GM, Burckhardt CS, Henriksson CM. Validity and reliability testing of the Quality of Life Scale, Swedish version in women with fibromyalgia - statistical analyses. Scand J Caring Sci. 2005; 19:64-70

33. Ware JE Jr, Sherbourne CD. The MOS 36-item Short-Form Health Survey (SF-36). I. Conceptual framework and item selection. Med Care. 1992;30:473-483.

34. Sullivan M, Karlsson J, Ware JE Jr. The Swedish SF-36 Health Survey-I. Evaluation of data quality, scaling assumptions, reliability and construct validity across general populations in Sweden. Soc Sci Med. 1995;41:1349-1358.

35. Consoli G, Marazziti D, Ciapparelli A, et al. The impact of mood, anxiety, and sleep disorders on fibromyalgia. Compr Psychiatry. 2012; 53:962-967

36. Liedberg GM, Henriksson CM. Factors of importance for work disability in women with fibromyalgia: an interview study. Arthritis Rheum. 2002;47:266-274

37. Liedberg GM, Björk M. Symptoms of subordinated importance in fibromyalgia when differentiating working from non-working women. Work. 2014;48(2):155-164.

38. Henriksson CM, Liedberg GM, Gerdle B. Women with fibromyalgia: work and rehabilitation. Disabil Rehabil. 2005;27:685-694.

39. Grönblad M, Nykänen J, Konttinen Y, Järvinen E, Helve T. Effect of zopiclone on sleep quality, morning stiffness, widespread tenderness and pain and general discomfort in primary fibromyalgia patients. A double-blind randomized trial. Clin Rheumatol. 1993;12:186-191.

40. Moldofsky H, Lue FA, Mously C, Roth-Schechter B, Reynolds WJ. The effect of zolpidem in patients with fibromyalgia: a dose ranging, double blind, placebo controlled, modified crossover study. J Rheumatol. 1996;23:529-533.

41. Veermeren A. Residual effects of hypnotics: epidemiology and clinical implications. CNS Drugs. 2004;18(5):297-328.

42. Simon GE, VonKorff M. Prevalence, burden, and treatment of insomnia in primary care. Am J Psychiatry. 1997;154:1417-1423.

43. Spaeth M, Rizzi M, Sarzi-Puttini P. Fibromyalgia and sleep. Best Pract Res Clin Rheumatol. 2011;25:227-239.

44. Rothman KJ. No adjustments are needed for multiple comparisons. Epidemiology. 1990;1:43-46.
Journal of Pain Research

\section{Publish your work in this journal}

The Journal of Pain Research is an international, peer-reviewed, open access, online journal that welcomes laboratory and clinical findings in the fields of pain research and the prevention and management of pain. Original research, reviews, symposium reports, hypothesis formation and commentaries are all considered for publication.

\section{Dovepress}

The manuscript management system is completely online and includes a very quick and fair peer-review system, which is all easy to use. Visit http://www.dovepress.com/testimonials.php to read real quotes from published authors. 